\title{
dspace.vutbr.cz
}

\section{Mass spectrometric imaging of cysteine rich proteins in human skin}

POMPEIANO VANIIČKOVÁ, L.; GURÁŇ, R.; KOLLAR, S.; EMRI, G.;

KŘIŽKKOVÁ, S.; DO, T.; HEGER, Z.; ZÍTKA, O.; ADAM, V.

International Journal of Biological Macromolecules

2019, vol. 125, March 2019, pp. 270-277

ISSN: 0141-8130

DOI: https://doi.org/10.1016/j.ijbiomac.2018.11.272

Accepted manuscript

(C) 2018. This manuscript version is made available under the CC-BY-NC-ND 4.0 license (http://creativecommons.org/licenses/by-nc-nd/4.0/), doi: https://doi.org/ 10.1016/j.jibiomac.2018.11.272

Final version available from

https://www.sciencedirect.com/science/article/pii/s0141813018356241 


\section{Mass Spectrometric Imaging of Cysteine Rich Proteins in Human Skin}

Lucie Vanickova ${ }^{\mathrm{a}, \mathrm{b}}$, Roman Guran ${ }^{\mathrm{a}, \mathrm{b}}$, Sándor Kollár ${ }^{\mathrm{c}}$, Gabriella Emri ${ }^{\mathrm{d}}$, Sona Krizkova ${ }^{\mathrm{a}, \mathrm{b}}$, Tomas Do ${ }^{\mathrm{a}}$, Zbynek Heger ${ }^{\mathrm{a}, \mathrm{b}}$, Ondrej Zitka ${ }^{\mathrm{a}, \mathrm{b}}$, Vojtech Adam ${ }^{\mathrm{a}, \mathrm{b}, *}$

${ }^{\text {a }}$ Department of Chemistry and Biochemistry, Mendel University in Brno, Brno, Czech Republic

${ }^{\mathrm{b}}$ Central European Institute of Technology, Brno University of Technology, Brno, Czech Republic

${ }^{\mathrm{c}}$ Kenézy Gyula County Hospital, Debrecen, Hungary

${ }^{\mathrm{d}}$ Department of Dermatology, University of Debrecen, Debrecen, Hungary

*Corresponding author: vojtech.adam@mendelu.cz 


\begin{abstract}
Looking insight pathological processes, metallothioneins (MTs) are considered to be potential biomarkers for monitoring of a development of various types of malignant disease, such as cancer. The early identification of the MT biomarkers in biological tissues could be important tool for the estimation of appropriate clinical therapy. Therefore here we investigated the application of matrix assisted laser desorption/ionization mass spectrometry imaging (MALDI MSI) together with immunohistochemical analyses (IHC) using MT-1/2 antibody for MT detection in formalin-fixed paraffin-embedded (FFPE) biopsy specimens of human skin. Principal component analyses revealed differences in the peptide/protein profiles separating healthy skin from the carcinoma specimens. Statistically significant ion peaks at $\mathrm{m} / \mathrm{z} 6038$, 6300, 6676, and 7026 were more frequently detected in squamous cell carcinoma (SCC), basal cell carcinoma (BCC) and melanoma. Using IHC, we found that MT-1/2 was significantly higher in SCC and melanoma compared to healthy skin. Surprisingly, significantly low levels of MT-1/2 were found in BCC. On one side, the results indicate important role of MTs in melanoma occurrence and progression, as on the second side, there are hidden processes associated with MTs based on differences of the occurrence of the MS peaks, which could be associated with cycling of MTs isoforms.
\end{abstract}

\title{
Keywords
}

metallothionein; squamous cell carcinoma; melanoma; MALDI MSI; immunohistochemistry 


\section{Introduction}

Our expertise on protein spatial detection has evolved massively in last two decades especially due to techniques of mass spectrometry (MS), liquid chromatography (LC), immunohistochemistry, fractionation and multiplex assays [1-5]. Recently the proteomics technologies have been applied for the analysis of formalin-fixed, paraffin-embedded (FFPE) tissues [6]. Given the stability of FFPE tissues following fixation, large number of hospitals keep archives of these tissues together with patient diagnosis and outcome [1]. Methods of LC-MS/MS and 2D gel electrophoresis have been previously used for the identification of proteins from FFPE tissues [7, 8]. Furthermore, laser microdissection method (LM) and/or hydrogel-based method represent other proteomic approaches allowing for investigation of regions of interest within a larger tissue sections [9-11]. For the ordinary proteomic procedure, it is necessary to extract sufficient amount of tissue proteins to enable the analyses and protein identification. Regarding the above mentioned techniques of LC-MS/MS and 2D gel electrophoresis, none of them provides spatially registered data of the identified peptides/proteins [11]. Matrix assisted laser desorption/ionization mass spectrometry imaging (MALDI MSI) is able to analyse the spatial distribution of molecules at or near the surface of complex substrates and have been widely used for biomarker discovery, tumour classification and for determination of the origin of the primary tumour [12, 13]. In addition, MSI is compatible with histopathological assessment to define diagnosis and support the following therapeutic management $[14,15]$. Immunohistochemistry (IHC) is a classical technique to study protein localization in tissues, as well as to confirm a protein's identity, and it is therefore complimentary to MALDI MSI studies [16].

Due to its efficient ability to grow, invade and metastasise, malignant melanomas are considered as one of the most aggressive malignancies resulting in $80 \%$ of mortalities from skin cancer. The treatment of metastatic melanoma is still limited, regardless recent successes 
of targeted therapies. For this reason understanding of disease progression, aiming at prediction of reaction to certain therapeutic treatments and identification of new therapeutic objectives is highly important [1].

Metalloproteins represent diverse class of proteins with metal-binding sites providing a structural, regulatory and catalytic function(s). An interesting group of metalloproteins, known as markers of metal poisoning and potential markers of tumour diseases, comprises a family of metallothioneins (MTs) $[17,18]$. In mammals, these low molecular mass cysteine rich proteins have four identified isoforms (MT-1 to MT-4) varying in expression and localization within individual tissues. $\mathrm{Zn}^{2+}$ naturally binds to the mammalian MT at its $\alpha$ - and $\beta$-domains, nevertheless it may be substituted for another metal ion, which has a higher affinity for thiolate. It is not surprising that mammalian MTs are involved in detoxifying, maintaining homeostasis and storage of metal ions. Based on recent findings one may summarize that MTs have critical regulatory impact on apoptosis, immunomodulation, transcription regulation, proliferation and enzyme activation via the administration of $\mathrm{Zn}$ ions to proteins and regulation of the concentration of free $\mathrm{Zn}^{2+}$. Based on these facts, MTs are considered as important biomarkers for zinc status and metal exposure and importantly they might serve for the prognosis of certain tumour diseases. In addition, an increased content of heavy metals and MTs in tumour tissues can be connected to the increased invasiveness and metastasizing of a tumour cells [19-21]. All these findings indicate that MTs could have a great potential as diagnostic, prognostic and predictive cancer biomarkers, however, it remains hidden and undiscovered. To confirm such hypotheses, robust analytical techniques are needed. Detection and determination of metallothioneins are challenging tasks for analytical chemistry, when electrochemistry, immunochemistry, mass spectrometric and others are often used [22, 23], however, to the best of our knowledge, an approach for detection of these proteins spatially in a tissue is missing. 
Therefore, a goal of the present study was to investigate the ability/suitability of MALDI MSI combined with IHC for detection of biological molecules in human skin tissues.

\section{Materials and Methods}

\subsection{Characterization of the samples}

This study was approved by the Kenézy Gyula County Hospital Ethics Committee (Debrecen, Hungary), and informed consent was obtained from all subjects. Normal skin was derived from an 83-year-old female patient, who had a keratoacanthoma on her forearm. The resection margin free of any tumour cells was used for the study. Basal cell cancer (basalioma solidum et cysticum) was localized on the shoulder of a 61-year-old male patient. Superficially spreading malignant melanoma with Breslow tumour thickness $2.76 \mathrm{~mm}$, Clark level III, 02/hpf mitotic activity (pT3a) was removed from the thigh of a 47 -year-old male patient. Grade 2 cutaneous squamous cell cancer of an 86-year-old female patient was localized on her nose. Melanocytic nevus was removed from the chest of a 45 -year-old female patient.

\subsection{Histology}

Formalin-fixed paraffin-embedded tissue blocks of various types of skin cancers were selected for MALDI MSI. Blocks of nevus and normal skin adjacent to a benign skin tumour were also included. All cases chosen for the study were diagnosed by a board-certified dermatopathologist. 4- $\mu \mathrm{m}$ sections were prepared from the tissue blocks and stained with haematoxylin-eosin for validation. Thereafter, 5- $\mu \mathrm{m}$ sections were cut and mounted onto ITOcoated glass slides. After drying, slides have been stored at room temperature until analysed.

\subsection{Immunohistochemistry}


$4-\mu \mathrm{m}$ sections mounted on coated (or charged) glass slides were deparaffinized and rehydrated. Endogenous peroxidase was blocked in $1 \%(v / v) \mathrm{H}_{2} \mathrm{O}_{2}$-methanol for $20 \mathrm{~min}$ at room temperature. Antigen retrieval was achieved by pressure-cooking the tissue samples in $10 \mathrm{mM}$ citrate buffer $(\mathrm{pH}=6)$. After the slides were cooled $(>10 \mathrm{~min})$, they were incubated with primary antibody for 1 hour at room temperature (MT-1/2 - clone E9, 1:50). For visualisation of the reaction, the horseradish peroxidase detection system and peroxide/DAB as substrates were used. The slides were counterstained with haematoxylin.

\subsection{MALDI MSI experiment}

The mass spectrometry imaging was performed on a MALDI-TOF/TOF mass spectrometer Bruker ultrafleXtreme (Bruker Daltonik GmbH, Bremen, DE). Broadband mass resolving power (RP) is up to 40,000 and the mass accuracy is $1 \mathrm{ppm}$. In total 10 ITO glass slides containing 20 tissue sections were analysed. MALDI matrix was sprayed onto ITO glass slides containing deparaffinized skin samples applying ImagePrep ${ }^{\mathrm{TM}}$ standard programs (Bruker Daltonik GmbH, Bremen, DE). Sinapinic acid (SA) and 2,5-dihydroxybenzoic acid (DHB) were used as MALDI matrices as follows: $10 \mathrm{mg} \mathrm{mL}^{-1} \mathrm{SA}$ in acetonitrile/water (60:40, $\mathrm{v} / \mathrm{v}$ ) with $0.2 \%$ trifluoroacetic acid (TFA) and $30 \mathrm{mg} \mathrm{mL}^{-1} \mathrm{DHB}$ in methanol/water (50:50, v/v) with $0.2 \%$ TFA. SA matrix was applied for the analyses of intact proteins, while DHB together with on-tissue trypsinization were used for peptide mapping. Prior analysis the slides were dried in vacuum desiccator for $15 \mathrm{~min}$. Scanned images of tissue slices were loaded into FlexImaging 3.0 software (Bruker Daltonik GmbH, Bremen, DE) and MALDI adapter with two ITO glass slides was loaded into mass spectrometer. The position of MALDI adapter was taught according to white teaching marks on ITO glass slides. Regions of acquisition were highlighted by mouse pointer in FlexImaging and $50 \mu \mathrm{m}$ raster width was chosen. The calibration was done externally using a peptide and protein standard mixture in the $\mathrm{m} / \mathrm{z}$ range 
0.5-20 kDa (Bruker Daltonik GmbH, Bremen, DE). The intensity of each scan, over the entire mass range acquired, was mapped on the tissue section image, allowing the visualization of the location of each $\mathrm{m} / \mathrm{z}$ value detected. A laser power was set $5-10 \%$ above the threshold. MALDI MSI of proteins was performed in linear positive mode in the $m / z$ range $1-20 \mathrm{kDa}$. MALDI MSI of tryptic peptides was performed in reflector positive mode in the $\mathrm{m} / \mathrm{z}$ range 0.5-5 kDa. 500 spectra were summed for each spot using the Random Walk raster pattern, with no evaluation criteria. The $m / z$ images were generated and visualized using SCiLS Lab 2014b software (SCiLS - Bruker Daltonik GmbH, Bremen, DE). Final corrections and preparations of the MALDI MSI images were carried out in GIMP 2.8 software.

For on-tissue trypsinization, one ITO glass slide with each type of tissue was used - in total, 5 ITO glass slides were used for trypsinization. Approximately, $300 \mu \mathrm{L}$ of trypsin solution (20 $\mu \mathrm{g} \mathrm{mL} \mathrm{m}^{-1}$ in $40 \mathrm{mM}$ ammonium bicarbonate, $0.1 \mathrm{mM} \mathrm{HCl}$ and $9 \%$ acetonitrile $\left.(v / v)\right)$ per one slide was applied by ImagePrep. Then, the slide was kept inside small box with humid atmosphere for 15 hours at $37^{\circ} \mathrm{C}$. Further, DBH matrix solution was applied. Prior MSI analysis the slide was dried in vacuum desiccator for $15 \mathrm{~min}$. The LIFT cell was used for MS/MS analysis of detected peptides [24].

\subsection{Statistical analysis of MSI data}

MSI data from FlexImaging were converted and uploaded into SCiLS Lab software that was used for pipeline pre-processing, segmentation and statistical analysis, mainly principal component analysis (PCA) with unit variance scaling, Anderson-Darling normality test and Kruskal-Wallis test. The data treatment was performed as described in detail in our previous study [25].

\section{Results}


The representative protein (Fig. 1A) and peptide (Fig. 1B) profiles of the five types of human skin tissues were characterised using histology-directed MALDI MSI approach of specified regions of interest (ROIs). The mean protein peak intensities were considerably lower than the mean peak intensities of peptides as expressed in pseudo-gel views. To investigate the differences among the protein/peptide profiles, PCA of ROIs was applied (Fig. 2). The first two axes counted for $63.82 \%$ and $50.75 \%$ of the total variability for proteins and peptides, respectively. Protein profiles of healthy skin (HS) tissue and naevus pigmentosus (NP) were similar, while the carcinoma tissues of basal cell carcinoma (BCC), squamous cell carcinoma (SCC) and malignant melanoma (MM) were separated from the healthy specimens among the first axis (Fig. 2A). The overall protein profile similarities among the ROIs of the three types of skin cancer tissues resulted in overlapping of the BCC, SCC, and MM. The relative intensities of ion peaks at $\mathrm{m} / \mathrm{z} 4376,4879,5154,6038,6300,6676,7026$ and 14065 varied significantly and were responsible for the separation of healthy skin tissues from cancer tissues (Fig. 2B). Peptide profiles were able to differentiate SCC from the remaining tissue types along the PC1 axis, while $\mathrm{HS}, \mathrm{BCC}$ and MM were partially separate from each other along the PC2 axis (Fig. 2C). Peptide $m / z$ specific for MM were 1106 and 1461, for SCC tissue was characteristic the presence of $\mathrm{m} / \mathrm{z}$ at 1199, 2182, and 2421. BCC and HS tissues were separated from each other by specific peptides at $m / z 1586$ and 616, respectively (Fig. 2D).

In protein profiles, the PCA and Kruskal-Wallis test indicated twelve statistically significant $(p<0.001)$ ion peaks (Supplementary Table 1) that were used for the formation of the MSI maps (Figs. 3, S1 and S2) and intensity box plots (Fig. 4s, S3 and S4). Primarily, we histologically examined the analysed samples (Fig. 3A), deparaffinised them (Fig. 3B) and detected the spatial distribution of four protein ion peaks at $\mathrm{m} / z$ 6038, 6300, 6676 and 7026 (Fig. 3C). The MSI images together with the intensity box plots demonstrate that all four 
selected $\mathrm{m} / \mathrm{z}$ ion peaks are significantly $(p<0.001)$ more expressed in SCC, BCC and MM than in HS or NP regions (Figs. 4 A-D). The ion peak at $m / z 6038$ was tentatively identified as MT-1 based on the comparison of the MT human apo-forms from UniProtKB database and confirmed by the results of IHC analyses. For the peptide identification, the LIFT method was applied, nevertheless the low signal intensities did not allow for peptide characterisation. In comparison, immunohistochemical detection of MT-1/2 was performed on the same normal skin and skin cancer samples as we used for MALDI MSI (Fig. 5). The photos of the tissue slices are shown in Fig. 5A. The photomicrographs labelled by red rectangle are magnified in Fig. 5B and Fig. 5C, where histology and IHC staining are indicated, respectively. Intensive nuclear and cytoplasmic MT-1/2 presence was detected throughout the melanoma tissue. Highly proliferating cells at the invasive front of SCC also showed intensive staining, however, the expression of MT-1/2 seemed to disappear in more differentiated cancer cells. Basal cell cancer cells did not express MT-1/2. Moreover, the basal keratinocyte layer of epidermis was positively labelled with MT-1/2 antibody in both normal and tumour specimens (Fig. 5D).

The MSI images of six remaining statistically significant $m / z$ ions are shown in Fig. S1 and S2 together with intensity box plots (Figs. S3 and S4). SSC tissue was characteristic by higher abundance of in peaks at $m / z 3376$ and 3447, while $m / z$ 4376, 4879 and 5154 were detected in higher levels in SSC, BCC and MM when comparison with NP and NS. Ion peaks at $m / z$ 9323, 11422, and 14065 were overexpressed in $\mathrm{MM}$ and $\mathrm{m} / \mathrm{z} 9323$ was also significantly expressed in SCC tissue.

\section{Discussion}

The presented work aimed to establish an analytical methodology applying MALDI MSI together with IHC method for the detection of MT levels in biological tissues. In the present 
study we have chosen the skin specimens since the skin is the larges organ of human body being intensively exposed to insults that might result in benign to lift-threating diseases. The progression of the disease is characterized by the specific changes on molecular level representing a unique peptide/protein signatures that can be exploited to classify and correlate clinically relevant information for disease treatment $[25,26]$. Here we demonstrate that MALDI MSI technique together with IHC analyses is capable to successfully visualize spatial distribution of various proteins and peptides in FFPE tissues of human skin tumours and healthy skin. The novelty of the presented work relies on the combination of these two analytical techniques for possible application in clinical medicine. In analysing the cancer tissue by MALDI MSI, each of the peaks tentatively attributed to MTs can be monitored individually within single sample allowing for multiplex signature generation applied for improvement of skin cancer classification. Using suitable MSI statistical software, the significant mass peaks in the protein profiles were detected at $m / z 6038,6300,6676$ and 7026 $(p<0.001)$. The occurrence of peak at $\mathrm{m} / z 6038$ in tumour area was consistent with IHC staining for MT-1/2 in SCC, BCC and MM. IHC analyses using specific MT-1/2 antibody revealed elevated expression of MT-1/2 in SCC and MM. However, in BCC the MT-1/2 expression was negative. From the analytical point of view, the analysis of homogenised, digested tissue applying LC-MS/MS combined with electrospray ionization (ESI) would allow for effective protein/peptide separation [27]. Nevertheless during the tissue homogenization the spatial information of protein location is lost. Therefore recently developed hydrogel-based method for spatial protein extraction from FFPE tissue might be the right choice to overcome the aforementioned problem [11]. Regardless of the numerous advantages provided by identification of peptides/proteins by LC-MS/MS, the method of MALDI MSI could not be replaced considering the biomolecules imaging without the labelling and creation of multiple species images from one initial experiment $[28,29]$. Protein 
delocalisation across tissue sections together with the decreased sensitivity caused by oversampling are the two topics associated with the type of high spatial resolution imaging used in this study [16]. Delocalisation has been addressed here by the separation of matrix coating from analyte extraction through a recrystallization process using the ImagePrep. Despite the fact that numerous advances have been made to elevate the MALDI MSI spatial resolution ability, this remains one of the main restrictions of the technique [30].

The conditions used here for the MALDI MSI experiments applying the DHB and SA matrices resulted in elimination of the metal ion from the MT. In our experiment, the calculated masses of human MT apo-forms according to the UniProtKB database are $6120 \mathrm{Da}$ for MT-1A, 6115 Da for MT-1B, 6014 Da for MT-1E, 6086 Da for MT-1F, 6141 Da for MT1G, 6039 Da for MT-1H, 6062 Da for MT-1L (1R), 6110 Da for MT-1K (1M), 6068 Da for MT-1X, 6042 Da for MT-2A, 6927 Da for MT-3 and 6509 Da for MT-4. In human skin, MTs were previously identified mainly by IHC analyses and/or molecular gene expression methods. Expression human skin, all major human MT isoforms (MT-1, MT-2, MT-3 and MT-4) have been found [31]. Due to a high sequence and structural similarity of MT-1 subisoforms, their distinguishing on the protein level is complicated. Therefore, their expression is mostly evidenced on the mRNA level. This is however not fully consistent with the translated proteins mostly due to possible RNA silencing or turnover. Despite that, several studies have described MTs encoding mRNA as plausible biomarkers of pathophysiological states. For instance, active expression of $M T 1 G, M T-1 H$ and $M T-2 A$ genes was found in human skin fibroblasts after exposure to $\mathrm{Cd}^{2+}[32]$, up-regulation of $M T-1 F, M T-1 X, M T-1 E$ and MT-2A genes was found as a consequence of exposure of human keratinocytes to nontoxic concentrations of $\mathrm{Zn}^{2+}$ [33] and expression of $M T-1 A, M T-1 G, M T-1 F, M T-1 X$ and $M T-2 A$ was found to be decreased in proliferating keloid fibroblasts compared to normal fibroblasts. Contrary to that, expression of $M T-1 A, M T-1 E, M T-1 F$ and $M T-2 A$ was found to 
be increased in keloid keratinocytes compared to normal keratinocytes [34]. Noteworthy, no evidence on expression of $M T-1 B, M T-1 L, M T-1 M$ in normal skin was found. The keratinocytes in the basal layer of the epidermis constitutively express MT-1, whereas the spinous layer is characterised by MT-4 expression [35]. Low MT-3 protein expression has been demonstrated in normal skin epidermis [36, 37]. Aiming our attention at malignant processes, it has been described that changes in MTs levels might play a role in the conversion of a potentially malignant lesion to a malignant carcinoma. Significantly higher $M T-1 / 2$ and $M T-3$ expression was noted in actinic keratosis and cutaneous squamous cell cancer, as compared with normal skin epidermis, whereas very low levels of $M T-3$ expression were found in BCC [21, 36-38]. In superficial and nodular BCC a decreased/absent expression of $M T-1 / 2$ could be demonstrated, whereas an increased $M T-1 / 2$ expression was found in infiltrative type BCC $[39,40] . M T-1 / 2$ over-expression has been found in cutaneous malignant melanomas in association with poor prognosis [41, 42]. Over-expression of cancertestis antigen 16 (CT16, PAGE5), a positive regulator of MT-2A has been demonstrated in melanoma metastasis [43]. Upregulation or moderate to intense expression of $M T-3$ was observed in melanoma and SCC [36, 37]. Nevertheless, MT-1E gene promoter hypermethylation causing decrease in MT1E transcription can be found in 1 of 17 (6\%) of the benign naevi, in 16 of $43(37 \%)$ primary melanoma tumours and in 6 of $13(46 \%)$ melanoma metastases [44]. Higher incidence of promoter methylation of MT-1G was also demonstrated in melanomas compared with normal melanocytes and naevi [45].

Going deeper to the herein obtained data, MSI analyses together with IHC [46] suggest that one of the four ion peaks at $\mathrm{m} / \mathrm{z} 6038$ might belong to cysteine-rich metal-binding protein, MT, as IHC staining and MSI intensity was consistent with the tumour tissue of melanoma and the invasive front of SCC. On the other hand, very low levels of MT-1/2 expression were found by IHC in BCC that is consistent with the hypothesis that expression of MTs could be 
also correlated with the epithelium stratification. Our data demonstrate that basal layer cells reveal lower expression of MTs compared to more differentiated cells of the suprabasal layers, which is in accordance of the results published by Pula et al. [36]. However, it is hard to conclude on the reason of a discrepancy in MT-1/2 levels analysed by IHC and MALDI MSI in BCC, when we hypothesize that MALDI MSI can identify all expressed sub-isoforms of MTs, which could not be detected using antibodies due to the non-existence of antibodies to all MTs isoforms. All these facts demonstrate the marked complexity of a role of MTs in skin biology. Despite the fact that an expression of mRNA encoding for MTs can be utilized as biomarker for diagnostic or prognostic purposes, only a proper quantitation and identification of translated protein can bring novel insights into the importance of MTs in skin cancer pathogenesis.

Taking into consideration all of the previous discussion, it would seem that an alternative workflow may be proposed, whereby IHC, LC-MS, SALD ICP MS and MALDI MSI are used as complementary techniques $[47,48]$. This more objective approach may notably decrease the timescale for biomarker discovery studies. Furthermore, we believe that the combination of different MS techniques together with IHC could lead to a description of differential expression of various sub-isoforms of MTs and substantially contribute to understanding of BCC pathogenesis. Moreover, recently applied technique immuno-MALDI (iMALDI) MS that uses anti-peptide antibodies for the specific enrichment of targeted analytes and on-target detection of the captured analytes [49], could be another solution for MT isoforms identification in FFPE tissues. We are keen to further investigate this challenging aspect employing LC-MS/MS technique together with MALDI MS and MSI to identify the spatial distribution of all available sub-isoforms expressed in BCC specimens.

\section{Conclusions}


In conclusion, our results contributed to the basic knowledge on protein distribution in histologically specified regions in skin cancer tissues and would be used in further experiments aiming at elucidation of processes involved in skin carcinogenesis. We highlight the potential value of high-resolution images that allow for the evaluation of cutaneous, malignant melanoma and basal cell cancer proteomic details unreachable using other lowerresolution investigative techniques. It is felt that the number of proteins identified and imaged could be improved if a strategy combining the analysis of tissue homogenates by LC- MS/MS (for identification purposes) together with SALD ICP MS and MALDI MSI for distribution analysis were employed. This will be the subject of further studies.

\section{Acknowledgement}

This research has been financially supported by the Internal Grant Agency of Mendel University in Brno (project No. AF-IGA-2018-tym005), by the Ministry of Education, Youth and Sports of the Czech Republic under the project CEITEC 2020 (LQ1601). VA wishes to express his thanks to the European Research Council (ERC) under the European Union's Horizon 2020 research and innovation programme (grant agreement No 759585). LV was supported by project 6SA17676 that received funding from the European Union's Horizon 2020 research and innovation programme under the Marie Skłodowska-Curie and which is co-financed by the South Moravian Region under grant agreement No. 665860.

\section{Disclosure}

The authors report no conflicts of interest in this work. 


\section{Captions for Figures}

\section{Figure 1}

Pseudo-gel view for mean mass spectra from (A) protein ROIs, and (B) peptides ROIs in five different skin tissues. The triangles indicate $\mathrm{m} / \mathrm{z}$ depicted in the PCA loading plots in Fig. 2 .

\section{Figure 2}

(A) PCA scores plot of protein ROIs. (B) PCA loading plot of protein ROIs. (C) PCA scores plot of peptide ROIs. (D) PCA loadings plot of peptide ROIs. Green - normal skin, purple naevus pigmentosus ROI, blue - squamous cell carcinoma ROI, red - basal cell carcinoma ROI, orange - malignant melanoma. Numbers in the loading plots indicate statistically significant $m / z(p<0.001)$.

\section{Figure 3}

Histological and MSI analysis of five different skin tissues, namely normal skin, naevus pigmentosus, squamous cell carcinoma ( $\mathrm{SCC}$ ), basal cell carcinoma (BCC), and malignant melanoma (MM). (A) Representative histological photomicrograph showing the particular tissue type. (B) Scanned pictures of the particular tissue type after the deparaffinization together with selected regions of interest (ROIs) used for MSI analysis. (C) Protein maps for ion peaks at $m / z 6038,6300,6676$ and 7026 generated as “ $[\mathrm{m} / \mathrm{z}] \pm 10 \mathrm{Da}$ ", scale bar $=1 \mathrm{~cm}$.

\section{Figure 4}

Intensity box plots of selected protein $\mathrm{m} / \mathrm{z}$ values (A) 6038, (B) 6300, (C) 6676 and (D) 7026 in five different skin tissues.

\section{Figure 5}


Immunohistochemical (IHC), histological and MSI analysis of squamous cell carcinoma (SCC), basal cell carcinoma (BCC) and malignant melanoma (MM). (A) Representative photomicrograph showing increased (brown colour) or decreased MT-1/2 immunoreactivity in specific skin tissues. (B) Magnified histological photomicrograph showing the selected area (red rectangle) of the particular tissue type. (C) Magnified photomicrograph showing increased (brown colour) or decreased MT-1/2 immunoreactivity in specific skin tissues in the selected area (red rectangle). (D) Protein maps for ion peaks at $m / z, 6038,6300,6676$ and 7026 overexpressed in SSC, BCC and MM in the selected area (red rectangle), generated as “ $[\mathrm{m} / \mathrm{z}] \pm 10$ Da". Scale bar $=2 \mathrm{~mm}$. 


\section{Supplementary Table}

\section{Table S1}

Statistically significant ion peaks identified in protein profiles that account for the variation between five regions of interest (ROIs) in the studied skin specimens.

\section{Supplementary Captions for Figures}

\section{Figure S1}

Protein maps for $m / z$ 3376, 3447, 4376 and 4879 Da. All $\mathrm{m} / \mathrm{z}$ images were generated as “ $[\mathrm{m} / \mathrm{z}]$ $\pm 10 \mathrm{Da}$

\section{Figure S2}

Protein maps for $m / z$ 5154, 9323, 11422 and $14065 \mathrm{Da}$. All $\mathrm{m} / \mathrm{z}$ images were generated as "[m/z] $\pm 10 \mathrm{Da} "$

\section{Figure S3}

Intensity box plots in all ROIs for $m / z$ (A) 3376, (B) 3447, (C) 4376 and (D) 4879 Da.

\section{Figure S4}

Intensity box plots in all ROIs for $m / z$ (A) 5154, (B) 9323, (C) 11422 and (D) 14065 Da. 


\section{References}

[1] P. Dowling, B. Moran, E. Mcauley, P. Meleady, M. Henry, M. Clynes, M. Mcmenamin, N. Leonard, M. Monks, B. Wynne, P. Ormond, A. Larkin, Oncol. Lett., 12 (2016) 3296-3304. [2] A. Gloger, D. Ritz, T. Fugmann, D. Neri, Cancer Immunol. Immunother., 65 (2016) 1377 1393.

[3] S.K. Kailasa, H.-F. Wu, Analyst, 135 (2010) 1115-1123.

[4] S.K. Kailasa, H.-F. Wu, Analyst, 137 (2012) 1629-1638.

[5] S.K. Kailasa, H.-F. Wu, Talanta, 114 (2013) 283-290.

[6] O.J.R. Gustafsson, G. Arentz, P. Hoffmann, BBA-Proteins Proteomics, 1854 (2015) 559580.

[7] S.A. Luebker, M. Wojtkiewicz, S.A. Koepsell, Proteomics, 15 (2015) 3744-3753.

[8] J.J. Kennedy, J.R. Whiteaker, R.M. Schoenherr, P. Yan, K. Allison, M. Shipley, M. Lerch, A.N. Hoofnagle, G.S. Baird, A.G. Paulovich, J. Proteome Res., 15 (2016) 2717-2728.

[9] H. Hinneburg, P. Korac, F. Schirmeister, S. Gasparov, P.H. Seeberger, V. Zoldos, D. Kolarich, Mol. Cell. Proteomics, 16 (2017) 524-536.

[10] A. Azimi, K.L. Kaufman, M. Ali, S. Kossard, P. Fernandez-Penas, Cancer Genomics Proteomics, 13 (2016) 453-465.

[11] D. Taverna, A.C. Pollins, L.B. Nanney, G. Sindona, G.M. Caprioli, Exp. Dermatol., 25 (2016) 143-146.

[12] M.R.L. Paine, P.C. Kooijman, G.L. Fisher, R.M.A. Heeren, F.M. Fernández, S.R. Ellis, J. Mat. Chem. B, 5 (2017) 7444-7460.

[13] A.C. Crecelius, U.S. Schubert, F. von Eggeling, Analyst, 140 (2015) 5806-5820.

[14] J. Oetjen, D. Lachmund, A. Palmer, T. Alexandrov, M. Becker, T. Boskamp, P. Maass, Anal. Bioanal. Chem., 408 (2016) 6729 - 6740.

[15] R. Longuespee, R. Casadonte, M. Kriegsmann, C. Pottier, G.P. de Muller, P. Delvenne, J. Kriegsmann, E. De Pauw, Proteom. Clin. Appl., 10 (2016) 701-719.

[16] C.S. de Macedo, D.M. Anderson, K.L. Schey, Talanta, 174 (2017) 325-335.

[17] P. Babula, M. Masarik, V. Adam, T. Eckschlager, M. Stiborova, L. Trnkova, H. Skutkova, I. Provaznik, J. Hubalek, R. Kizek, Metallomics, 4 (2012) 739-750.

[18] A. Krężel, W. Maret, Int. J. Mol. Sci., 18 (2017) 1237-1257.

[19] S. Krizkova, M. Ryvolova, J. Hrabeta, V. Adam, M. Stiborova, T. Eckschlager, R. Kizek, Drug Metab. Rev., 44 (2012) 287-301.

[20] J. Gumulec, V. Adam, R. Kizek, M. Masarik, PLoS One, 9 (2014) 1-14.

[21] S. Krizkova, M. Kepinska, G. Emri, T. Eckschlager, M. Stiborova, P. Pokorna, Z. Heger, V. Adam, Pharmacol. Ther., 183 (2018) 90-117.

[22] S. Krizkova, M. Kepinska, G. Emri, M.A.M. Rodrigo, K. Tmejova, D. Nerudova, R. Kizek, V. Adam, J. Pharm. Biomed. Anal., 117 (2016) 464-473.

[23] V. Adam, I. Fabrik, T. Eckschlager, M. Stiborova, L. Trnkova, R. Kizek, TRAC-Trends Anal. Chem., 29 (2010) 409-418.

[24] D. Suckau, A. Resemann, M. Schuerenberg, P. Hufnagel, J. Franzen, A. Holle, Anal. Bioanal. Chem., 376 (2003) 952-965.

[25] R. Guran, L. Vanickova, V. Horak, S. Krizkova, P. Michalek, Z. Heger, O. Zitka, V. Adam, PLoS One, 12 (2017) 1-15.

[26] A. Walch, S. Rauser, S.-O. Deininger, H. Höfler, Histochem. Cell Biol., 130 (2008) 421434.

[27] G.W. Irvine, M.J. Stillman, BBA-Proteins Proteomics, 1866 (2018) 589-601. 
[28] A. Thomas, S. Lenglet, P. Chaurand, J. Deglon, P. Mangin, F. Mach, S. Steffens, J.-L. Wolfender, C. Staub, Thromb. Haemost., 106 (2011) 20-30.

[29] R.M. Caprioli, J. Am. Soc. Mass Spectrom., 26 (2015) 850-852.

[30] P.J. Hart, S. Francese, M.N. Woodroofe, M.R. Clench, Int. J. Ion Mobil. Spec., 16 (2013) 71-83.

[31] C. Ma, L.F. Li, X. Chen, Br. J. Dermatol., 164 (2011) 479-482.

[32] J.M. Prins, L. Fu, L. Guo, Y. Wang, J. Proteome Res., 13 (2014) 1677-1687.

[33] E. Emri, E. Miko, P. Bai, G. Boros, G. Nagy, D. Rózsa, T. Juhász, C. Hegedüs, I. Horkay, E. Remenyik, G. Emri, Metallomics, 7 (2015) 499-507.

[34] P.P.-C. Toh, J.J. Li, Y.G. W.-C, S.-L. Lo, C.H. Guo, T.-T. Phan, B.-H. Bay, Exp. Dermatol., 19 (2010) 987-993.

[35] H.M. McGee, G.M. Woods, B. Bennett, R.S. Chung, Photochem. Photobiol. Sci., 9 (2010) 586-596.

[36] B. Pula, T. Tazbierski, A. Zamirska, B. Werynska, A. Bieniek, J. Szepietowski, J. Rys, P. Dziegiel, M. Podhorska-Okolow, Pathol. Oncol. Res., 21 (2015) 187-193.

[37] A. Slusser, Y. Zheng, X.D. Zhou, S. Somji, D.A. Sens, M.A. Sens, S.H. Garrett, Toxicol. Lett., 232 (2015) 141-148.

[38] A. Zamirska, L. Matusiak, P. Dziegiel, G. Szybejko-Machaj, J.C. Szepietowski, Pathol. Oncol. Res., 18 (2012) 849-855.

[39] K. Rossen, T. Haerslev, K. Hou-Jensen, G.K. Jacobsen, Br. J. Dermatol., 136 (1997) 3034.

[40] A. Bieniek, B. Pula, A. Piotrowska, M. Podhorska-Okolow, A. Salwa, M. Koziol, P. Dziegiel, Folia Histochem. Cytobiol., 50 (2012) 352-357.

[41] E. Emri, K. Egervari, T. Varvolgyi, D. Rozsa, E. Miko, B. Dezso, I. Veres, G. Mehes, G. Emri, E. Remenyik, J. Eur. Acad. Dermatol. Venereol., 27 (2013) e320-e327.

[42] G. Weinlich, K. Eisendle, E. Hassler, M. Baltaci, P.O. Fritsch, B. Zelger, Br. J. Cancer, 94 (2006) 835-841.

[43] C. Nylund, P. Rappu, E. Pakula, A. Heino, L. Laato, L.L. Elo, P. Vihinen, S. Pyrhönen, G.R. Owen, H. Larjava, M. Kallajoki, J. Heino, PLoS One, 7 (2012) 1-12.

[44] W.J. Faller, M. Rafferty, S. Hegarty, G. Gremel, D. Ryan, M.F. Fraga, M. Esteller, P.A. Dervan, W.M. Gallagher, Melanoma Res., 20 (2010) 392-400.

[45] Y. Koga, M. Pelizzola, E. Cheng, M. Krauthammer, M. Sznol, S. Ariyan, D. Narayan, A.M. Molinaro, R. Halaban, S.M. Weissman, Genome Res., 19 (2009) 1462-1470.

[46] L. Wehder, G. Ernst, A.C. Crecelius, O. Guntinas-Lichius, C. Melle, U.S. Schubert, F. von Eggeling, J. Histochem. Cytochem., 58 (2010) 929-937.

[47] J. Anyz, L. Vyslouzilova, T. Vaculovic, M. Tvrdonova, V. Kanicky, H. Haase, V. Horak, O. Stepankova, Z. Heger, V. Adam, Sci. Rep., 7 (2017) 1-13.

[48] K. Coufalikova, I. Benesova, T. Vaculovic, V. Kanicky, J. Preisler, Anal. Chim. Acta, 968 (2017) 58-65.

[49] R. Popp, M. Basik, A. Spatz, G. Batist, R.P. Zahedi, C.H. Borchers, Analyst, 143 (2018) 2197-2203. 
Normal skin

Naevus

pigmentosus

Squamous cell carcinoma

Basal cell

carcinoma

Malignant

melanoma

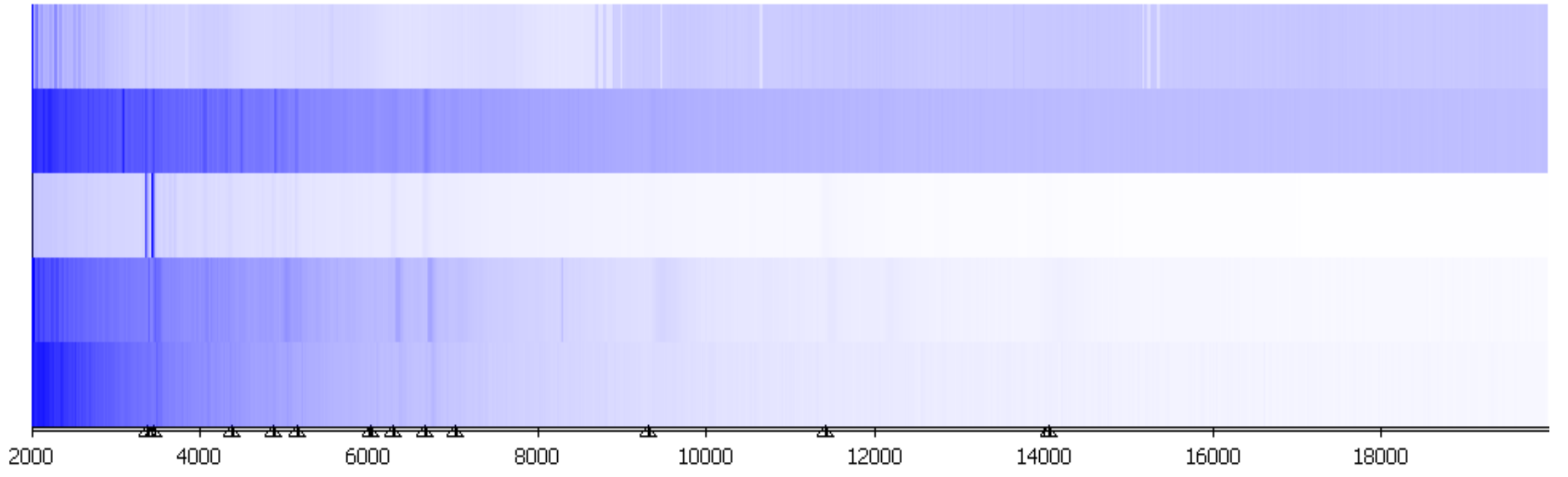

B

Normal skin

Naevus

pigmentosus

Squamous cell carcinoma

Basal cell carcinoma

Malignant

melanoma
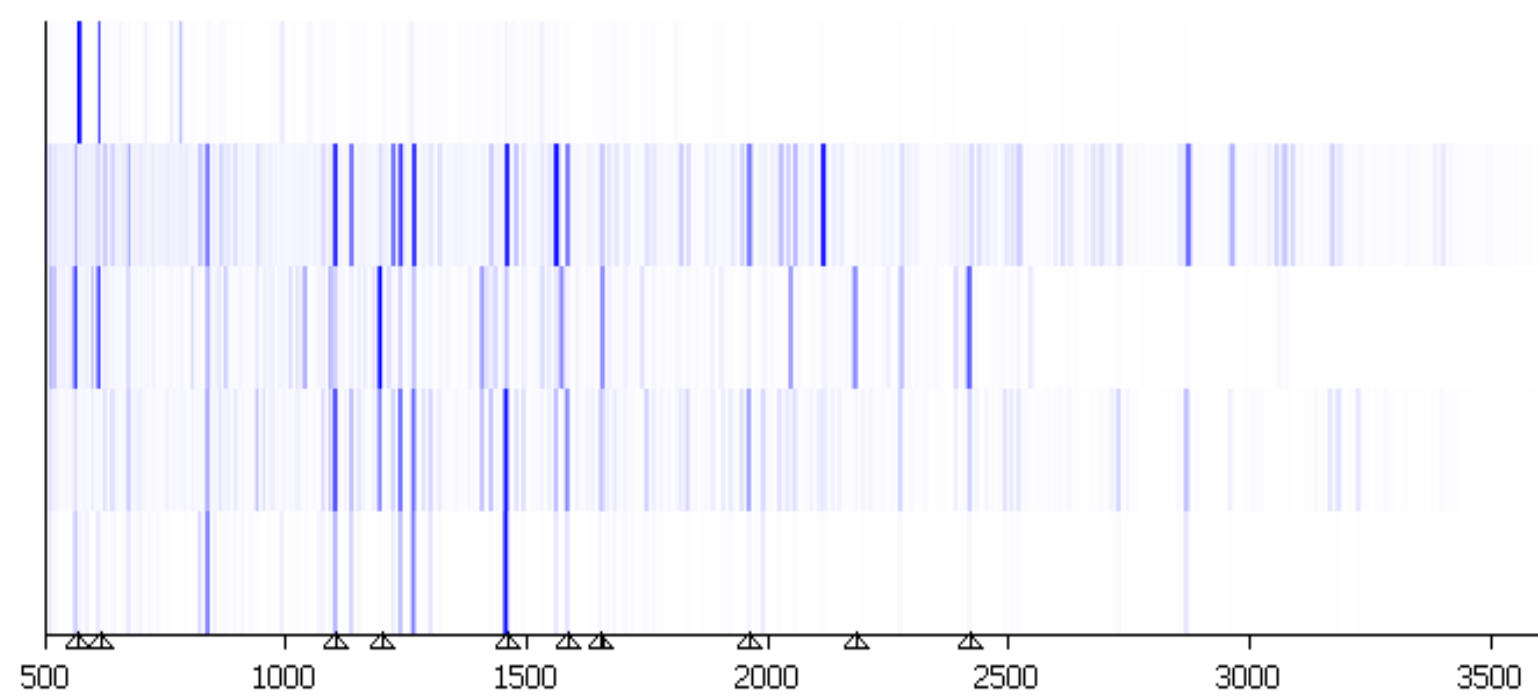

3500

4500

5000 

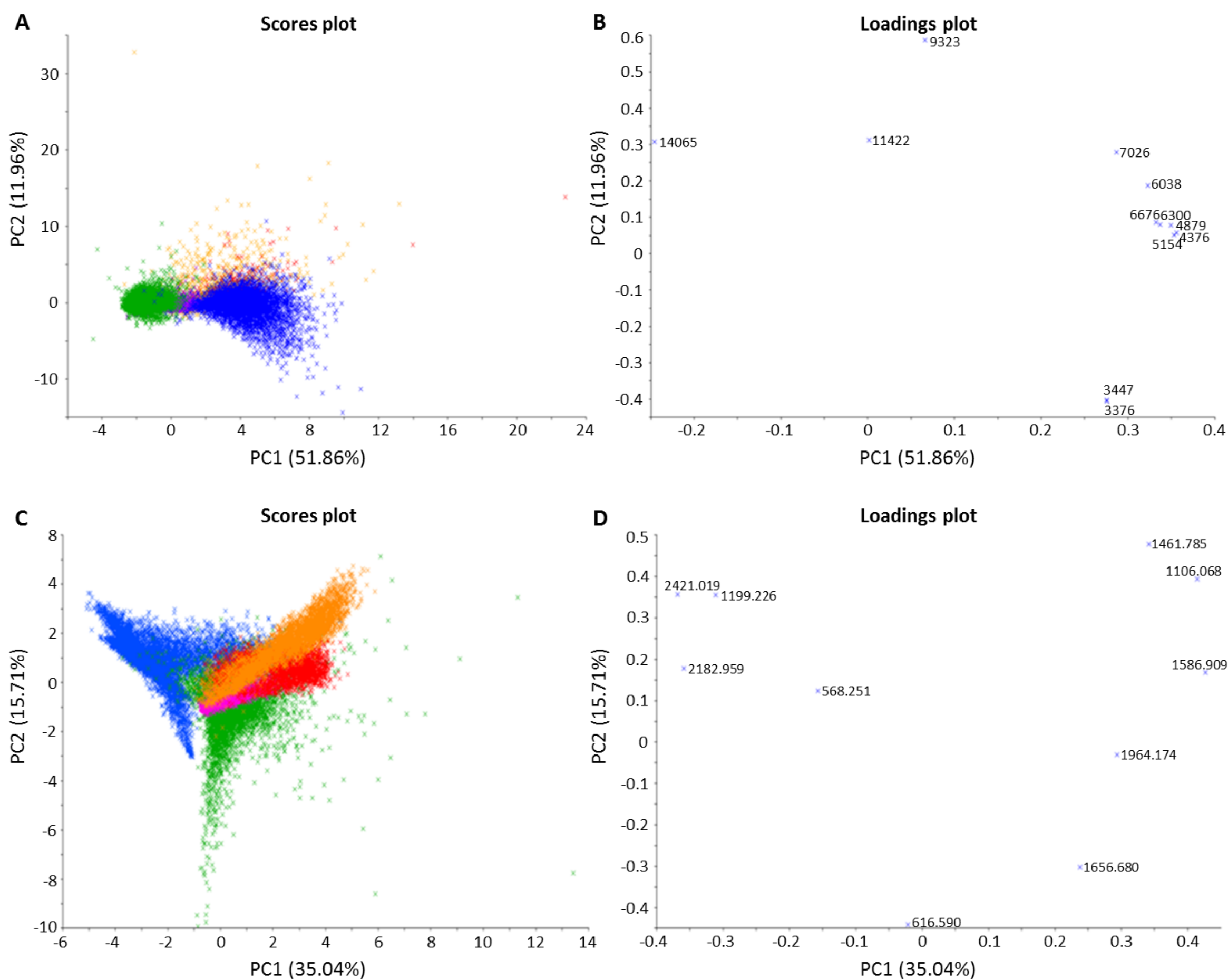
A

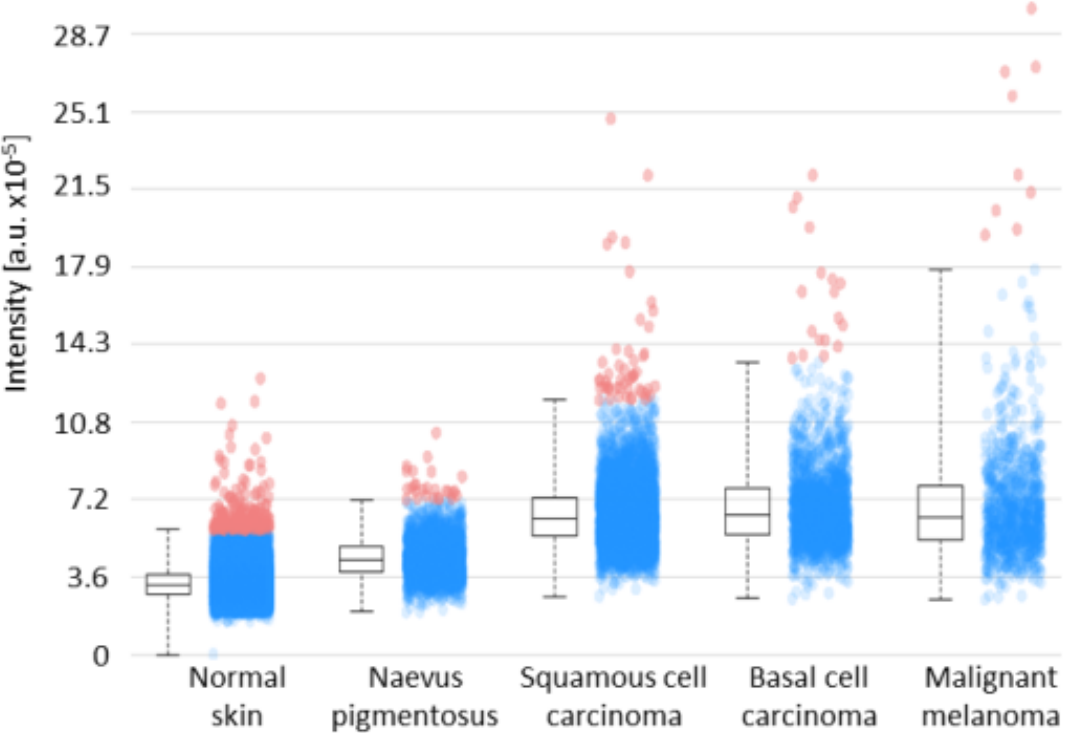

C 56.6 m/z $6676 \mathrm{Da}$

50.3



25.2

18.9
12.6

6.3 6.3
0<smiles>C1CC2CCC(C1)C2</smiles>

9

$6-20$

$0 \quad$
33.9

m/z 6300 Da

30.1

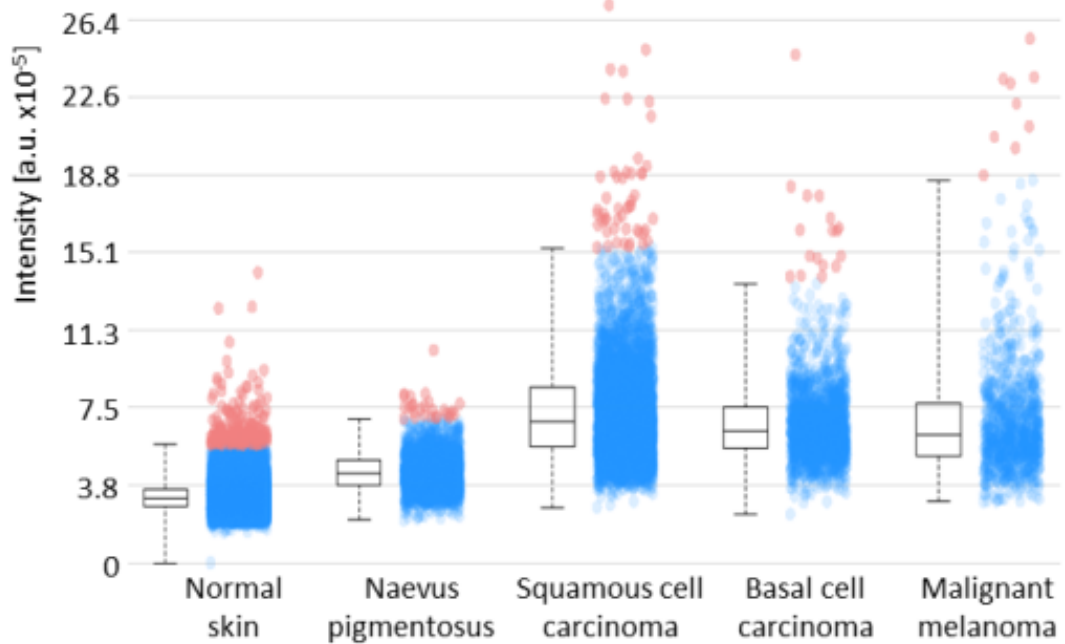

D 69.6

$\mathrm{m} / \mathrm{z} 7026 \mathrm{Da}$

61.9

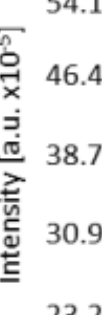

23.2

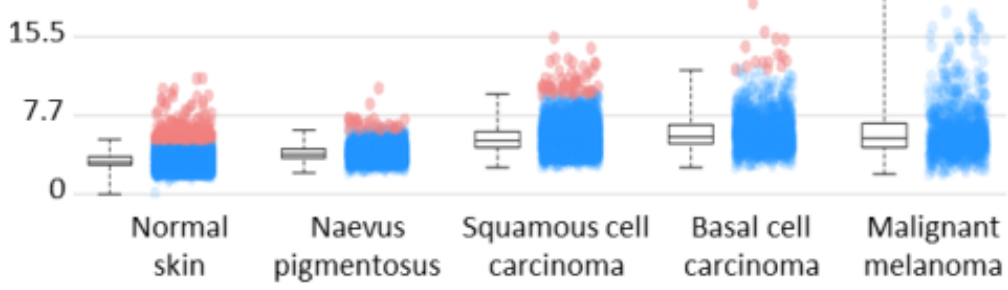




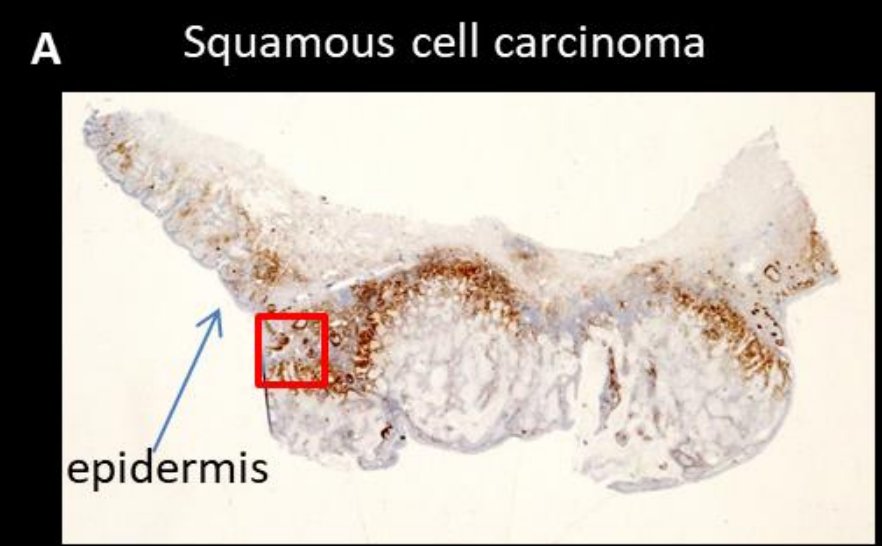

Basal cell carcinoma

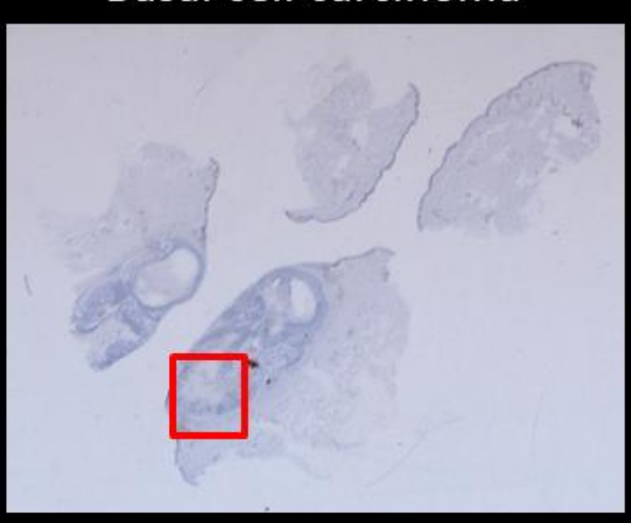

Malignant melanoma



$2 \mathrm{~mm}$

ש

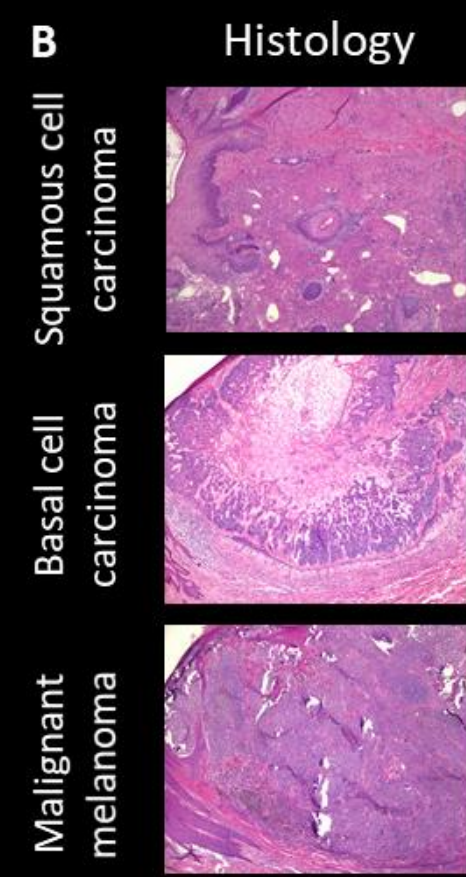

C

IHC
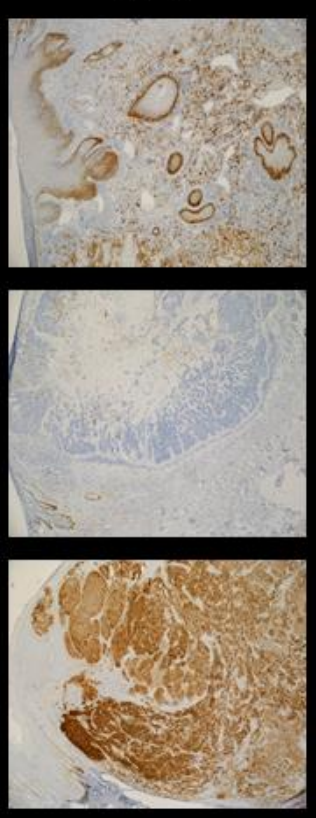

D $\mathrm{m} / \mathrm{z} 6038 \mathrm{Da}$
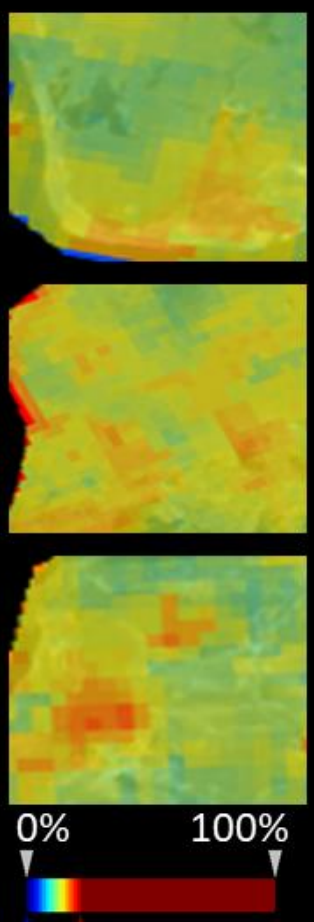

$0 \% 21 \%$ m/z $6300 \mathrm{Da}$
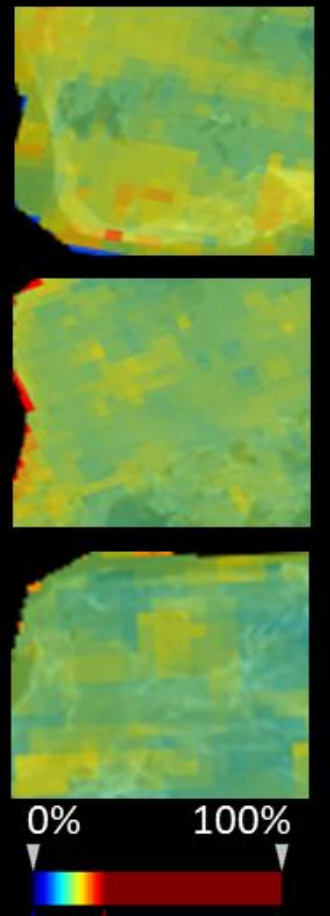

$0 \% 28 \%$ m/z $6676 \mathrm{Da}$
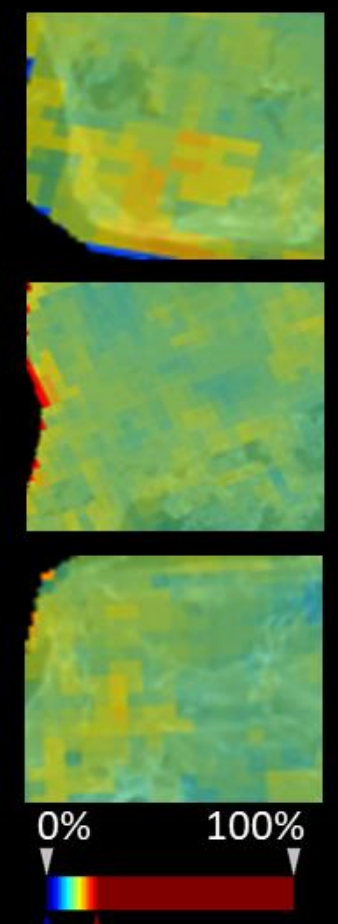

0\%20\% m/z 7026 Da


0\%13\% 







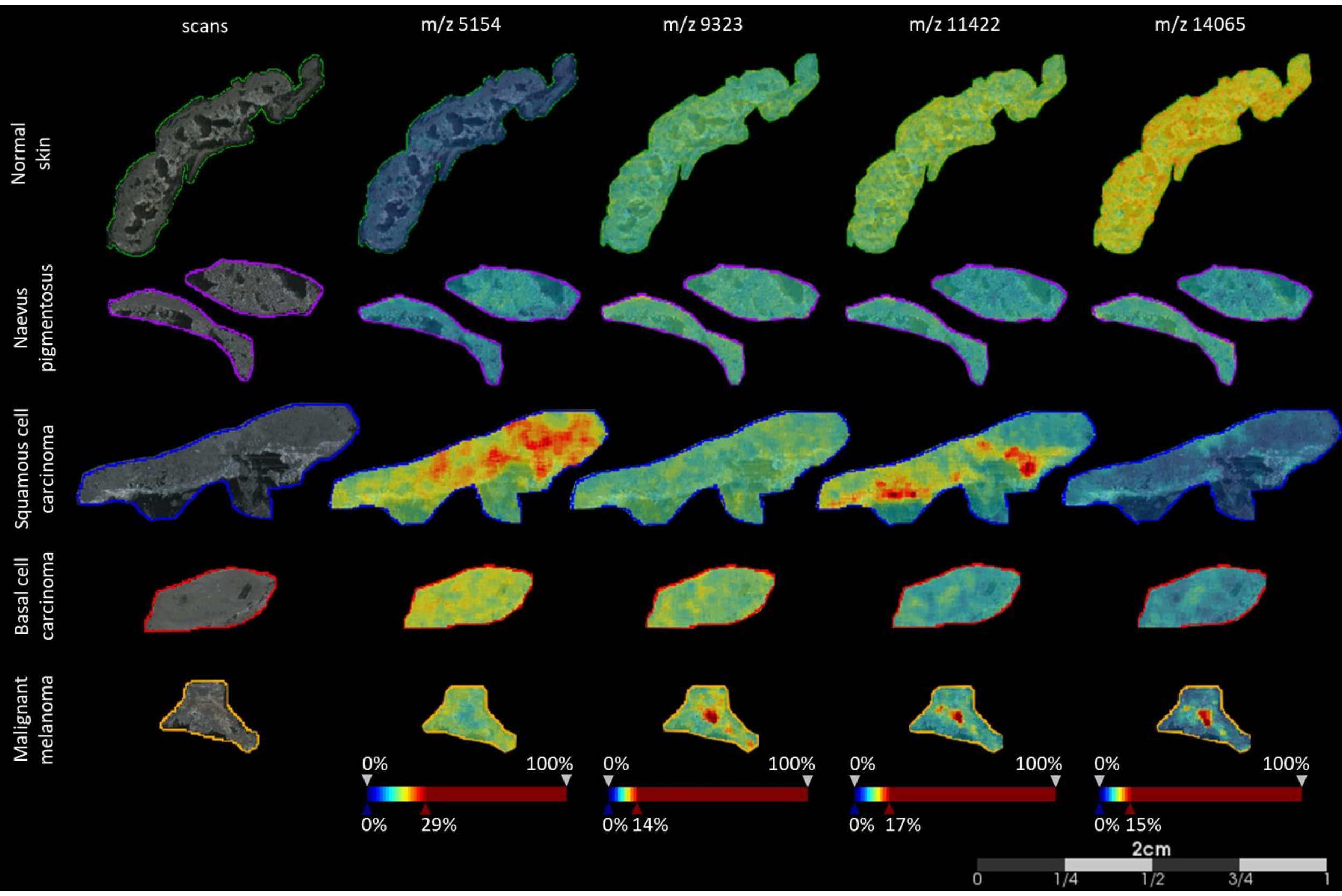


A

368.8

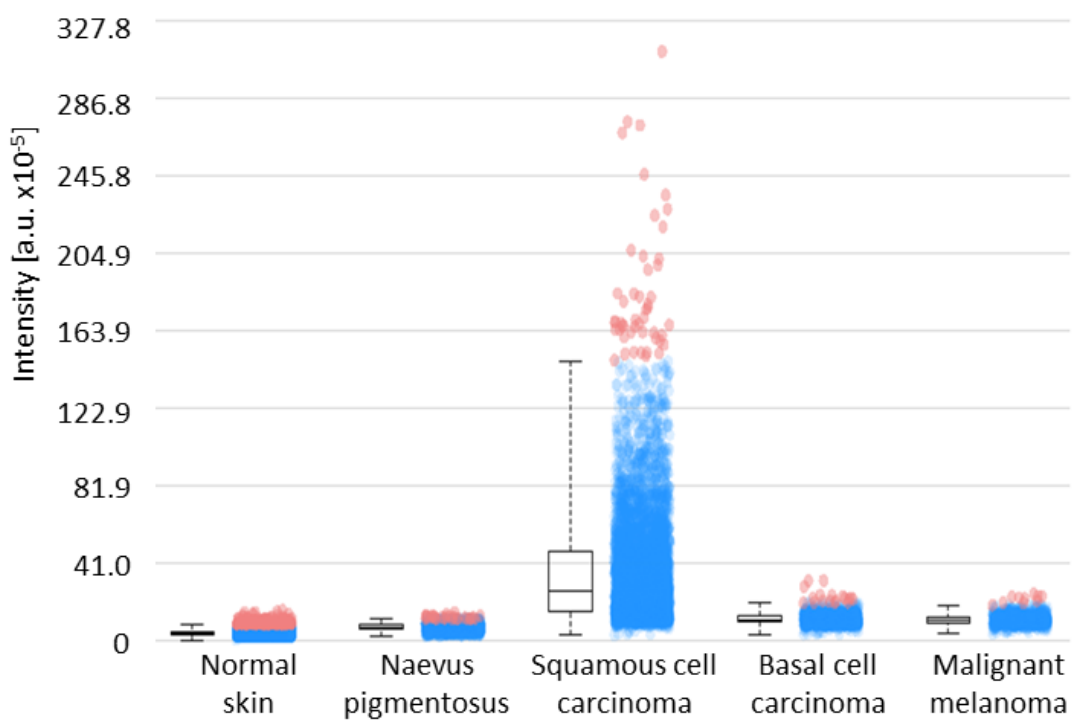

C

\section{3}

m/z $4376 \mathrm{Da}$

30.5

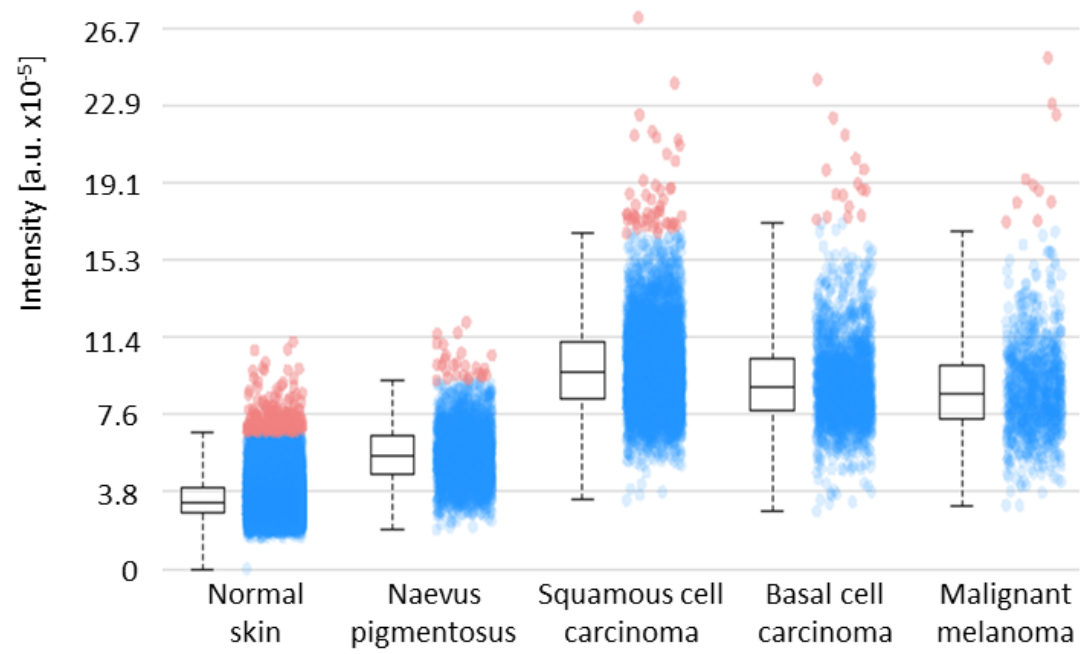

B

332.1

295.2



D

63.2

m/z $4879 \mathrm{Da}$

56.2

49.2

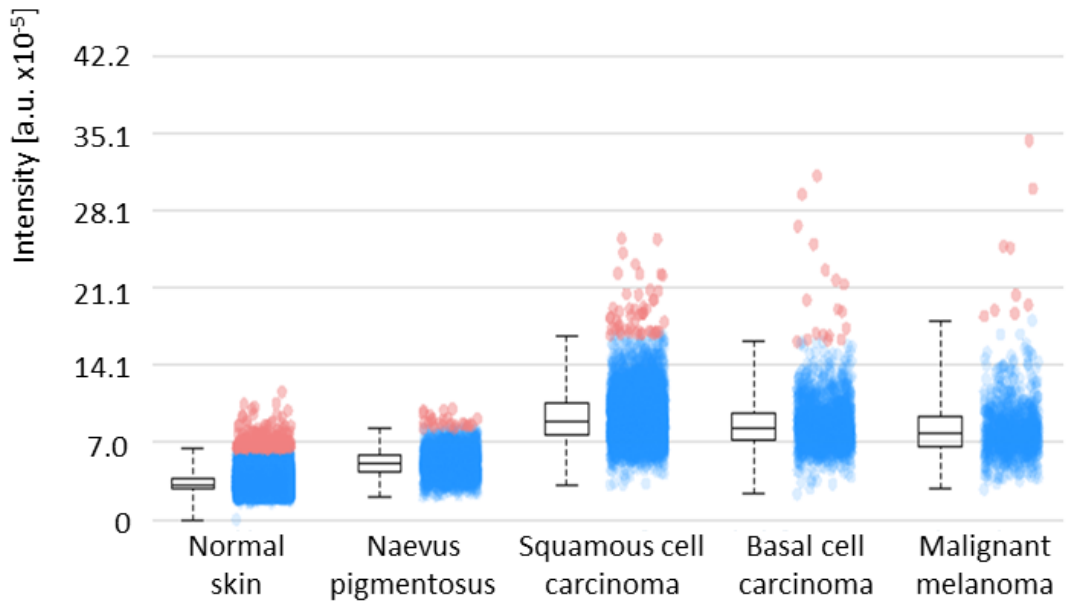


A $30.6 \quad \mathrm{~m} / \mathrm{z} 5154 \mathrm{Da}$

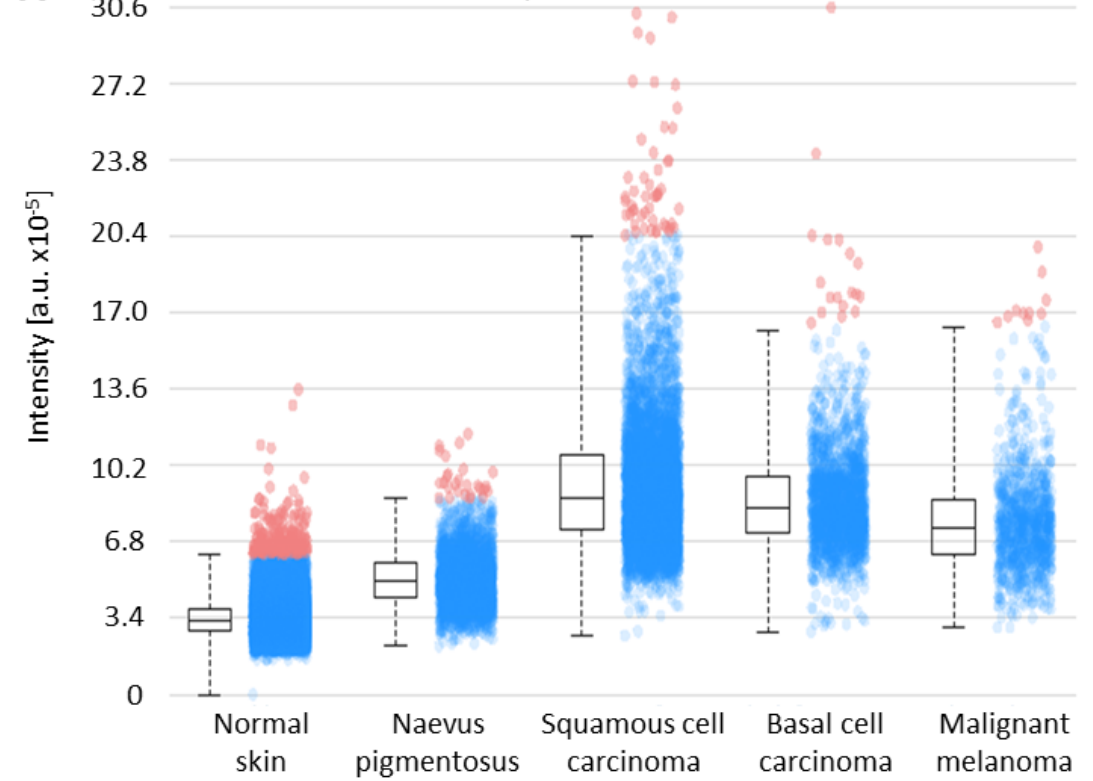

C
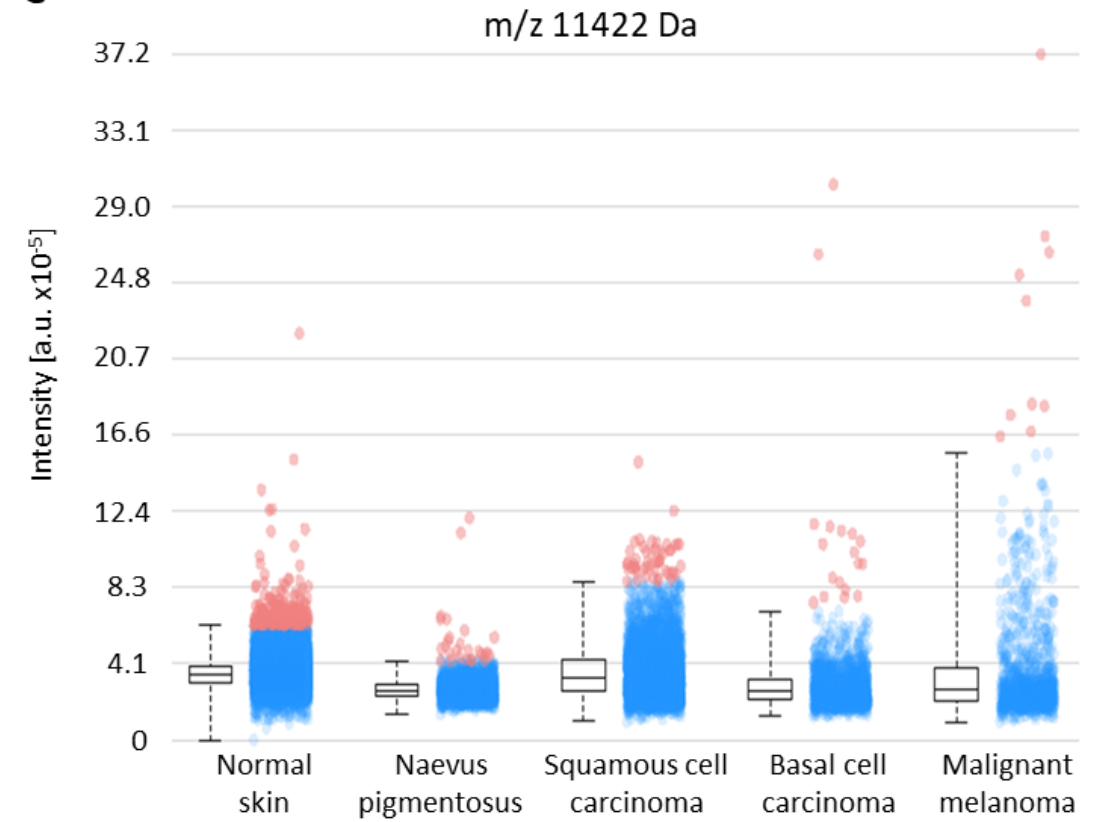

B $\mathrm{m} / \mathrm{z} 9323 \mathrm{Da}$

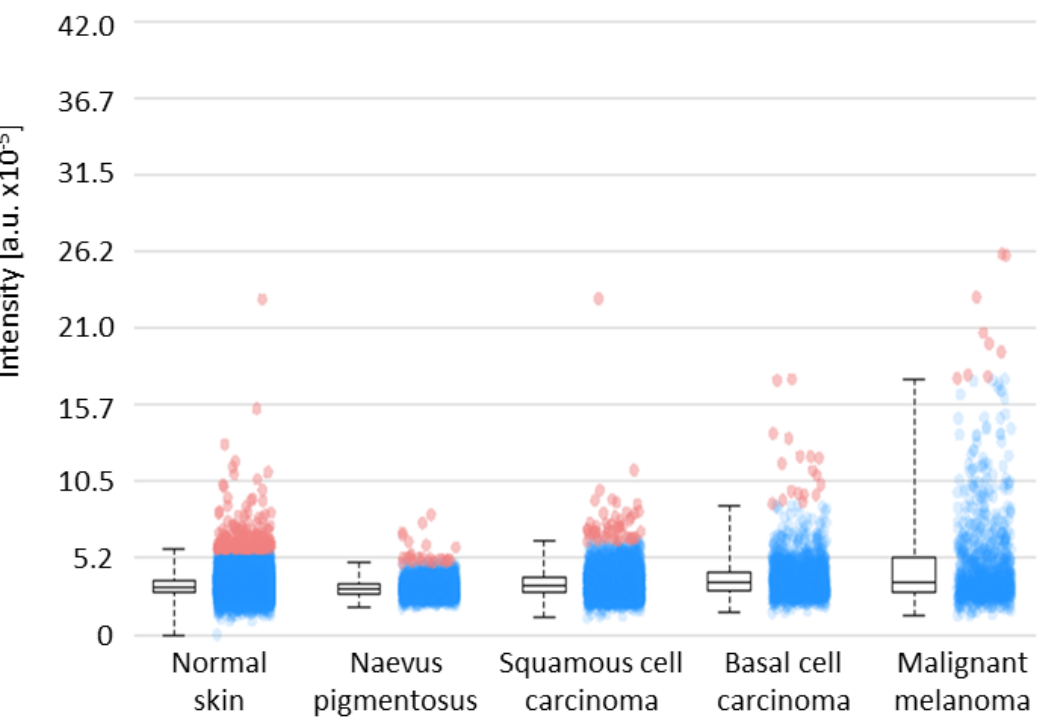

D

$37.9-\mathrm{m} / \mathrm{z} 14065 \mathrm{Da}$

33.7

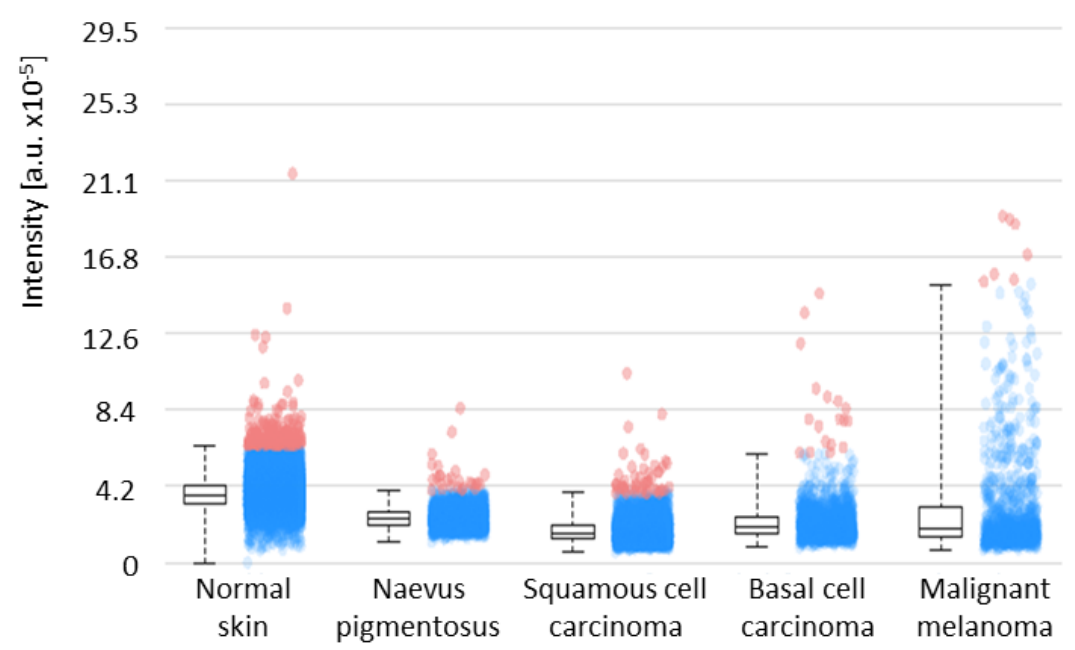

